\title{
Congenital Presentation of a Solitary Superficial Angiomyxoma in the Parotid Region Masquerading as Parotid Tumor
}

\author{
Shailaja SHUKLA, Shivali SEHGAL, Pawani PRABHAT, Khushboo DEWAN
}

Department of Pathology, Lady Hardinge Medical College, DELHI, INDIA

\begin{abstract}
Superficial angiomyxoma is a rare cutaneous and benign lesion. We present a case of congenital presentation of a superficial angiomyxoma in the parotid region in a 9-year- old female that was misdiagnosed as a parotid tumor. Appropriate diagnosis is important since such lesions have a good prognosis and rarely affect deeper structures. Possibility of superficial angiomyxoma should be kept in mind in the differential diagnosis of lesions of the parotid region.
\end{abstract}

Key Words: Congenital, Superficial angiomyxoma, Parotid

\section{INTRODUCTION}

Superficial angiomyxoma is a rare cutaneous, benign lesion that is still poorly recognized. When located in the parotid region, it can easily be misdiagnosed as a parotid tumor. It is located in the dermis with frequent extension to the subcutis. It is multilobulated and individual nodules show moderate to sparse cellularity with a background of myxoid stroma (1-3). This case is being reported because of the congenital presentation of a solitary superficial angiomyxoma in the parotid region, which is rare.

\section{CASE REPORT}

A 9-year-old girl presented with a swelling below the right ear, which was present since birth and was gradually increasing in size. There was no relevant medical history. On examination a $3 \times 2 \mathrm{~cm}$ firm, mobile, non tender mass was palpable below the right pinna at the angle of the mandible, in the parotid region. The overlying skin was normal. No lymph nodes were palpable. Fine needle aspiration cytology was performed and showed abundant fibromyxoid stroma. A possibility of pleomorphic adenoma was suggested, although no epithelial component was seen. The mass was excised through a superficial parotidectomy incision. A globular grey brown tissue measuring $3 \times 2 \times 1 \mathrm{~cm}$ was received. It was encapsulated and the cut surface was soft and gelatinous. On microscopy, many variable blood vessels separated by fibromyxoid stroma were seen (Figure 1). There was presence of stellate cells, muciphages, mucin,

(Turk Patoloji Derg 2018, 34:262-264)

Received : 04.02.2016 Accepted : 25.04.2016 neutrophils and lymphocytes in the stroma (Figure 2). There was no mitosis, hyperchromasia or pleomorphism. The features were consistent with the diagnosis of superficial angiomyxoma. No parotid tissue was identified in any of the sections examined. The stroma was $\mathrm{CD} 34$ and SMA positive and S-100, pancytokeratin and desmin negative, blood vessels were CD34 positive on immunohistochemistry. General physical examination, imaging studies and laboratory findings were noncontributory. There was no evidence of any pigmented skin lesions, endocrine tumors or overactivity, schwannomas or myxomas elsewhere, ruling out Carney's complex. A final diagnosis of a congenital, solitary superficial angiomyxoma of the parotid region was made. Subsequently, the patient was lost to follow up.

\section{DISCUSSION}

Superficial angiomyxoma, first described in 1988 (1) is a rare benign, cutaneous tumor of adolescents and adults that has a predominant occurrence in the region of the maxillary and mandibular bones (2). In the head and neck region, it has been described on the head, lower eyelid, preauricular region, external ear and upper alveolus $(3,4)$. Rarely, congenital occurrences have been reported (5). Histologically, superficial angiomyxoma is a dermalbased lesion with frequent extension to the subcutis. It is multilobulated, with poorly defined margins. Individual nodules are moderately to sparsely cellular with copious basophilic interstitial material. Spindle and stellate cells are

Correspondence: Shivali SEHGAL

Department of Pathology, Lady Hardinge Medical College, DELHI, INDIA E-mail: shivalisehgal@gmail.com Phone: +98 18770874 


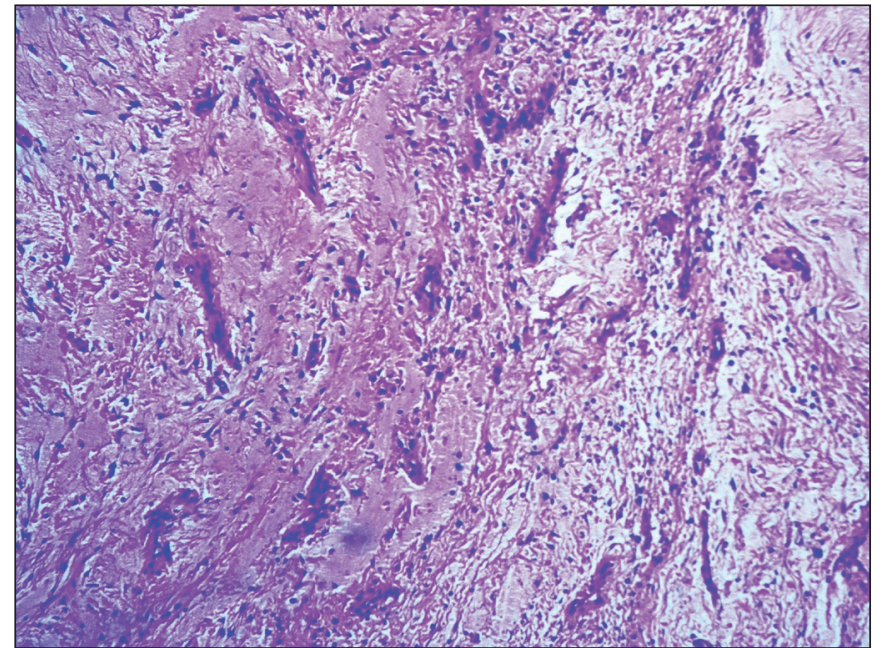

Figure 1: Many variable blood vessels separated by fibromyxoid stroma (H\&E; x200).

seen in the myxoid stroma. Mitotic activity is sparse. Rarely, epithelial component is seen and represents entrapped adnexal structures or adjacent squamous epithelium (3).

Superficial angiomyxomas in the parotid region are extremely rare. Rodriguez et al have previously reported one such case in the parotid region in a 61-year-old male (6).

The differential diagnosis includes benign and lowgrade malignant myxoid lesions including aggressive angiomyxoma, focal cutaneous mucinosis, myxoid neurothekeomas, myxoid neurofibroma, acral fibromyxoma and myxoid liposarcoma (7). It is important to differentiate it from these lesions since superficial angiomyxoma has a propensity for local recurrence.

Aggressive angiomyxoma is larger, situated deep, usually in the female pelvis and the blood vessels are large, thick walled and prominent. Focal cutaneous mucinosis lacks lobular architecture, epithelial structures and neutrophils in the stroma. Superficial acral angiomyxoma is almost exclusively found on the fingers and toes in middle age and lacks a neutrophilic infiltrate (8). Myxoid neurothekeoma has a prominent lobular growth pattern and is characterized by plump cells that are S-100 positive. Myxoid neurofibroma has cells with buckled nuclei that are S-100 positive. Myxoid liposarcomas are deeply situated and larger with chicken wire vascular pattern and lipoblasts. Myxofibrosarcoma has more marked nuclear atypia and hyperchromasia with presence of curvilinear blood vessels lined by cells with hyperchromatic nuclei (7).

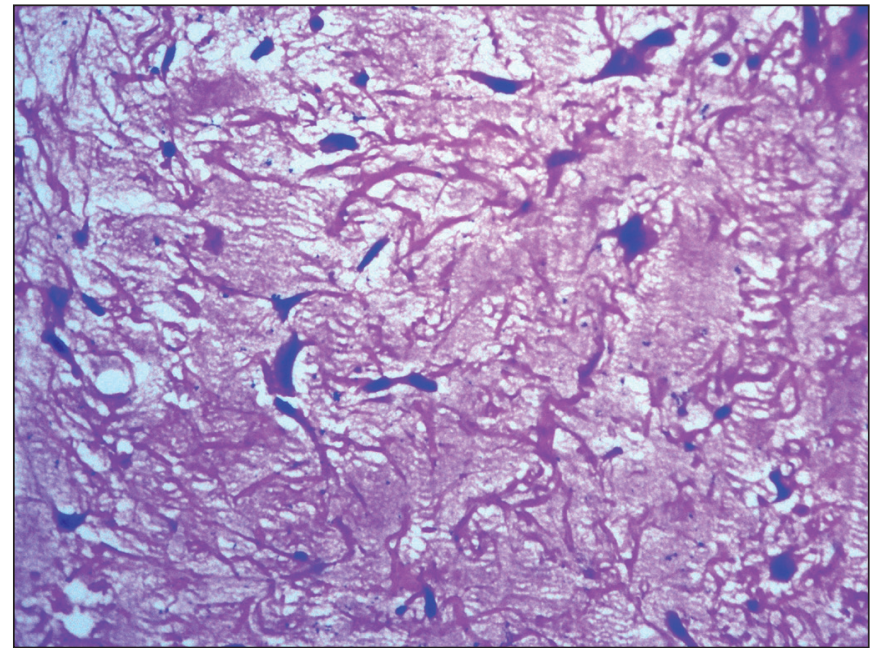

Figure 2: Presence of stellate cells, spindle cells and lymphocytes in the stroma (H\&E; $\mathrm{x} 400)$.

At this site, the differential diagnosis includes parotid gland tumors as well as cysts of the first branchial arch (5). Fine needle aspiration cytology can be confusing as in our case.

Superficial angiomyxomas have an overall good prognosis as these lesions remain superficial without affecting deeper structures. Appropriate diagnosis, complete surgical treatment and close follow up are advised.

In conclusion, the case highlights the importance of distinguishing superficial angiomyxomas from other lesions that occur in the parotid region. One should be cautious about reporting pleomorphic adenoma on smears showing abundant fibromyxoid stroma.

\section{CONFLICT OF INTEREST}

The authors declared no conflict of interest.

\section{REFERENCES}

1. Allen PW, Dymock RB, Mac Cormac LB. Superficial angiomyxomas with or without epithelial components. Report of 30 tumors in 28 patients. Am J Surg Pathol. 1988;12:519-30.

2. Rosanowski F, Walther EK. Pre-auricular angiomyxoma in a child. Laryngorhinootologie. 1993;72:618-20.

3. Khadilkar UN, Khadilkar NP, Rao PS, Chakravorty S, Goel G. Superficial angiomyxoma of the external ear not associated with Carney's complex: A case report. Kathmandu Univ Med J. 2007;5:546-9.

4. Ravindra SV, Raju MS, Sunitha JD, Taneja N, Chandra S, Mahajan S, Panwar E. Intraoral superficial angiomyxoma of the upper alveolus: Report of a unique case. Cas Rep Med. 2012;2012:859021.

5. Bedlow AJ, Sampson SA, Holden CA. Congenital superficial angiomyxoma. Clin Exp Dermatol. 1997;22:237-9. 
6. Rosado Rodríguez P, de Vicente JC, de Villalaín L, Blanco V. Superficial angiomyxoma of the parotid region and review of literature. Acta Otorrinolaringol Esp. 2012;63:147-9.

7. Shanthi V, Rama Krishna BA, Rao NM, Reddy RS, Chandra Sekhar BHP, Venkata Harish C. Superficial angiomyxoma with epithelial component - a rare cutaneous myxoid tumour. J Biosci Tech. 2011;2:318-23.
8. Fetsch JF, Laskin MB, Miettinen M. Superficial acral fibromyxoma: A clinicopathologic and immunohistochemical analysis of 37 cases of distinctive soft tissue tumors with a predilection fingers and toes. Hum Pathol. 2001;32:704-14. 